Conclusions An evidence based practice leads to improve blood sampling in VLBW infants. Post intervention results are still to be measured.

\section{PO-0899 THE IMPLEMENTATION RATE OF DEVELOPMENTAL CARE IN IRANIAN NICUS}

'ZZ Godarzi, ${ }^{2} \mathrm{O}$ Rahimi, ${ }^{3} \mathrm{~N}$ Khalesi, ${ }^{4} \mathrm{~A}$ Shamshiri, ${ }^{5} \mathrm{~N}$ Mohammadi. ${ }^{1}$ Neonatal Intensive Group, Faculty Nursing and Midwifery of Tehran University of Medical Sciences, Tehran, Iran; ${ }^{2}$ Neonatal Intensive Care Unit, Bahrami Hospital Tehran University of Medical Sciences Tehran Iran (E-Mail, Tehran, Iran; ${ }^{3}$ Medicin Teaching, Associate Professor School of Medicine Tehran University of Medical Sciences., Tehran, Iran; ${ }^{4}$ Epidemiologist Unit, Dentistry Research Institute and Department of Community Oral Health School of Dentistry Tehran University of Medical Sciences, Tehran, Iran; ${ }^{5}$ Critical Care Group, Faculty Nursing and Midwifery Tehran University of Medical Sciences, Tehran, Iran

\subsection{6/archdischild-2014-307384.1522}

Background Nowadays, Developmental Centred Care in NeonatalIntensive Care Units (NICU) is expanding and being implemented in developedcountries in the form of scientific competition. The aim of this study was to evaluate the implementation rate of developmental centeredcare in NICUs in Tehran University of Medical Sciences hospitals in Tehran, Iran.

Methods A descriptive cross-sectional study was conducted in ninehospitals NICUs in 2012. The sample was included 138 nurses who had working intheir professional work. Using a selfadministrated questionnaire on coremeasure for checking the implementation of developmental care in NICUs anddemography characteristic.

Results The finding which indicated that, the highest rate ofdevelopmental centred care implementation, with $79.46 \%$ was routine care. Followed by sleep care $65.43 \%$, providing ahealthy environment $65.27 \%$ and family-centred care $63.32 \%$, respectively. Meanwhile,the lowest rate was $59.16 \%$ for the implementation of pain, stress managementand assessment.

Conclusion This study result which indicates that the implementationrate of the developmental centred care aspects in NICUs is low. Therefore,immediate actions should be taken for further promotion of developmental care,development of professional training and more importantly development ofinstruction and further research is needed.

\section{PO-0900 TRANSLATION COMFORTNEO - A PAIN ASSESSMENT TOOL}

R Stenkjaer, M Andersen, M Scheutz, Y Hundrup. Neonatalklinikken, Rigshospitalet University of Copenhagen, Copenhagen, Denmark

\subsection{6/archdischild-2014-307384.1523}

Background COMFORTneo scale is a pain assessment tool designed to assess the degree of pain for neonates. The scale is designed to assess the short term or long term pain. Centre for Clinical guidelines recommend the use of COMFORTneo systematic assessment of pain in newborns in Denmark. The instrument was originally developed in the Netherlands, but are published in an English edition.

Purpose The purpose of this poster is to describe how the pain assessment tool COMFORTneo has been translated into Danish and adapted to Danish conditions.

Method We have followed the principles recognised as good practice for the translation and cultural adaptation of an instrument from the source language into another language. This translation process involves eight steps: 1) Preparation 2) Forward translation 3) Comparison and critical review of the translations 4) Back Translation 5) Review of back translation 6) Adjustment of COMFORTneo to Danish conditions 7) Pilot Testing and 8) Proof and final adoption.

Results Translation and adaptation of COMFORTneo has been a fruitful process. Immediately, the applicability of COMFORTneo was confirmed through involvement of many nurses in the translation process. Involvement of nurses has been important and theese comments have contributed to the establishment of a Danish version of COMFORTneo that makes sense for Danish nurses.

Perspectives Following good practice for the translation and cultural adaptation, an instrument COMFORTneo is ready for implementation. This is of great importance as instruments of pain scoring of premature and sick newborns and are called for by many Danish neonatal departments.

\section{P0-0901 NEONATAL OUTCOMES OF ADOLESCENT PREGNANCIES IN A SECONDARY LEVEL MATERNITY HOSPITAL IN ROMANIA}

${ }^{1} \mathrm{LM}$ Suciu, ${ }^{1} \mathrm{M}$ Simon, ${ }^{2} \mathrm{R}$ Peti, ${ }^{2} \mathrm{M}$ Luca, ${ }^{1} \mathrm{M}$ Cucerea. ${ }^{1}$ Pediatrics, University of Medicine and Pharmacy Tirgu Mures, Tirgu Mures, Romania; ${ }^{2}$ Neonatology, County Hospital Tirgu Mures, Tirgu Mures, Romania

\subsection{6/archdischild-2014-307384.1524}

Background and aims Pregnant adolescents have high rates of poor birth outcomes, but the causes are unclear. There is a very marked association between young age of mothers and low birth weight and preterm delivery and some of the apparent effect of young maternal age on birth weight may be because the birth is likely to be the mother's first, and first births have a higher incidence of prematurity. The aim of present study was to investigate neonatal outcomes of teenage pregnancies controlling for parity, gestational age and perinatal interventions.

Methods A retrospective study comparing singleton deliveries classified into three teenage groups:12-15, 15-17, 18-19, and a comparison group of 24-29 years was performed in a secondary level Maternity Hospital in Mures County, Romania. For the adult group, 736 charts of mothers between the age of 24 and 29 delivering singleton babies were selected.

Results The study population consisted of 1131 women, 75 12-15 years old, 163 16-17 years old, 157 18-19 years old, and 736 24-29 years old. A significant linear association was found between maternal age and preterm birth, low birth weight, and neonatal birth related trauma. Length of hospitalisation, as a marker of the healthcare costs involved in the care of these high risk cases, was significant associated with maternal age after controlling for perinatal interventions.

Conclusions Teenage pregnancy is a risk factor for low birth weight, preterm delivery, neonatal birth related trauma and high healthcare costs.

\section{PO-0902 ANNP (ADVANCED NEONATAL NURSE PRACTITIONER) WORKFORCE: BALANCING SERVICE PROVISION AND TRAINING IN A LOCAL NEONATAL UNIT (NNU)}

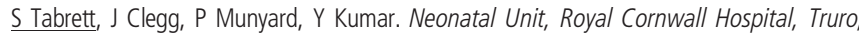
UK

10.1136/archdischild-2014-307384.1525 